ORIGINAL ARTICLE

\title{
Understanding parental motivators and barriers to uptake of child poison safety strategies: a qualitative study
}

\author{
L Gibbs, E Waters, J Sherrard, J Ozanne-Smith, J Robinson, S Young, A Hutchinson
}

Injury Prevention 2005;11:373-377. doi: 10.1136/ip.2004.007211

See end of article for authors' affiliations

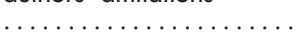

Correspondence to: Dr L F Gibbs, School of Health and Social Development, Deakin University, 221 Burwood Highway, Burwood 3125 Victoria, Australia; lisa. gibbs@deakin.edu.au

Accepted 4 August 2005

\begin{abstract}
Objectives: To develop an understanding of factors acting as barriers and motivators to parental uptake of child poison safety strategies.

Design: A qualitative study involving semistructured interviews and focus groups. A grounded theory approach was used for the collection and analysis of data.

Participants: Sixty five parents of children under 5 years of age, some of whom had experienced an unintentional child poisoning incident.

Results: A range of knowledge based, environmental, and behavioral barriers to comprehensive parental uptake of poison safety practices were identified. As a result there tended to be only partial implementation of safety initiatives in the home. Selection of safety practices was often guided by the interests and behaviors of the child. This made the child vulnerable to changes in the home environment, inadequate supervision, and/or shifts in their own behavior and developmental ability. Personal or vicarious exposure of a parent to a child poisoning incident was a significant motivator for parental review of safety practices. Conclusion: Environmental measures targeting child resistant containers, warning labels, and lockable poisons cupboards will support parents' efforts to maintain poison safety. Additional education campaigns using stories of actual poisoning incidents may help to increase awareness of risk and encourage increased uptake.
\end{abstract}

rather than being predetermined. Collection and analysis are carried out concurrently to allow each to influence the other, enabling further exploration of emerging themes. ${ }^{15} 16$

\section{Recruitment}

A total of 65 parents participated in this study through a series of 23 interviews and seven focus group discussions. Participants were recruited from the three different sources until saturation point was reached-that is, the data became repetitive with no new issues arising. Recruitment of a data rich sample was guided by the research focus (see table 1).

For those parents who had experienced a child unintentional poisoning incident, recruitment was selective (purposive sampling) to ensure that agents commonly involved in child unintentional poisoning were represented in the participant sample. All of the agents commonly involved in presentations to the RCHED ${ }^{17}$ and the VPIC $^{18}$ were included in the sample (see table 2), except for cardiovascular drugs which were not evident in the cases that arose during the recruitment period.

Recruitment of community groups was also selective (purposive sampling) in order to include parents from across Victoria including inner city, suburban, outer suburban, rural town, rural remote, and rural property to enable identification of commonalities across housing types. Information provided informally by participants in the course of interviews and discussions revealed that this selection process resulted in the recruitment of a diverse range of participants (see table 3). As demographic information was not collected systematically in the playgroup settings, specific numbers in each category cannot be provided. This is a limitation in the current study preventing detailed exploration of sociodemographic differences, which is further limited by the lack of

Abbreviations: CRC, child resistant container; RCHED, Royal Children's Hospital Emergency Department; VPIC, Victorian Poisons Information Centre 
Table 1 Recruitment and data collection process

\begin{tabular}{|c|c|c|c|c|c|}
\hline Research focus & Participant sample & Source & Recruitment method & $\mathbf{n}$ & Data collection mode \\
\hline $\begin{array}{l}\text { Circumstances of } \\
\text { poisoning incidents. } \\
\text { Poison safety strategies } \\
\text { being used }\end{array}$ & $\begin{array}{l}\text { Parents of children } \\
\text { under } 5 \text {; recent } \\
\text { unintentional } \\
\text { poisoning incident }\end{array}$ & RCHED & $\begin{array}{l}\text { Weekly keyword searches of ED } \\
\text { patient files by ED nurses. } \\
\text { Presenting parent contacted to } \\
\text { invite them to participate in the } \\
\text { research study }\end{array}$ & 10 & $\begin{array}{l}\text { Conducted by ED nurses: } \\
9 \text { interviews in the participants' home; } \\
1 \text { phone interview to overcome difficulties } \\
\text { arranging a home visit }\end{array}$ \\
\hline $\begin{array}{l}\text { Circumstances of } \\
\text { poisoning incidents. } \\
\text { Poison safety strategies } \\
\text { being used }\end{array}$ & $\begin{array}{l}\text { Parents of children } \\
\text { under } 5 \text {; recent } \\
\text { unintentional } \\
\text { poisoning incident }\end{array}$ & VPIC & $\begin{array}{l}\text { Relevant callers asked by VPIC } \\
\text { staff if they would accept a } \\
\text { follow up call re research study }\end{array}$ & 13 & $\begin{array}{l}\text { Conducted by project manager: } \\
\text { phone interviews }\end{array}$ \\
\hline $\begin{array}{l}\text { Poison safety strategies } \\
\text { being used }\end{array}$ & $\begin{array}{l}\text { Parents of children } \\
\text { under } 5\end{array}$ & $\begin{array}{l}\text { Community } \\
\text { playgroups }\end{array}$ & $\begin{array}{l}\text { Project manager arranged with } \\
\text { playgroup coordinator to visit the } \\
\text { group. Parents invited on arrival } \\
\text { to participate }\end{array}$ & 42 & $\begin{array}{l}\text { Conducted by project manager: } \\
7 \text { focus group discussions in playgroup } \\
\text { setting; } \\
1 \text { phone interview for a farmer on a remote } \\
\text { property }\end{array}$ \\
\hline
\end{tabular}

interpreter involvement. However, the focus of this study was on identification of commonalities across groups rather than variation between them.

The caregiver who contacted the VPIC, arrived at the RCHED, or participated in the playgroup was the one invited to participate in the study. In $97 \%$ of cases this was the mother. This gender weighting reflects the predominance of females as the primary caregiver in Australian society. ${ }^{19}$

The use of different data sources, methods of data collection, and investigators (see table 1) was necessary to capture the range of parent circumstances and poisoning experiences in a sensitive manner. It also represents an important triangulation technique within the study to ensure methodological rigour and research quality. ${ }^{20}$ This was further supported by comparison with related research findings as described in the discussion of the results.

\begin{tabular}{|c|c|}
\hline Recruitment source & Poisoning agents represented \\
\hline $\begin{array}{l}\text { Royal Children's Hospital } \\
\text { Emergency Department }\end{array}$ & $\begin{array}{l}\text { Paracetamol benzodiazepine } \\
\text { Thyroid medicine antihistamine } \\
\text { Cough and cold medicine } \\
\text { Essential oil } \\
\text { Migraine medicine corticosteroid } \\
\text { Selective serotonin reuptake inhibitor } \\
\text { (SSRI) antidepressant }\end{array}$ \\
\hline \multirow{6}{*}{$\begin{array}{l}\text { Victorian Poison Information } \\
\text { Centre }\end{array}$} & Toilet freshener \\
\hline & $\begin{array}{l}\text { Mineral turpentine } \\
\text { Antacid disinfectant }\end{array}$ \\
\hline & Oral contraceptive \\
\hline & $\begin{array}{l}\text { Calcium supplement } \\
\text { Essential oil paracetamol }\end{array}$ \\
\hline & Cough suppressant \\
\hline & Bath oil, bubble bath \\
\hline \multirow[t]{12}{*}{ Community playgroups } & Ethanol (non-beverage) \\
\hline & Oral contraceptive \\
\hline & Topical antiseptic bleach \\
\hline & Cleaner, miscellaneous \\
\hline & $\begin{array}{l}\text { Detergent, laundry } \\
\text { Polish furniture }\end{array}$ \\
\hline & Paracetamol \\
\hline & Petrol \\
\hline & $\begin{array}{l}\text { Cough and cold medicine } \\
\text { Toilet freshener }\end{array}$ \\
\hline & Auto dishwasher detergent \\
\hline & Vitamins compound (no iron) \\
\hline & Sedative/hypnotic \\
\hline & $\begin{array}{l}\text { All purpose/hard surface cleaner } \\
\text { Non-steroidal anti-inflammatory drug }\end{array}$ \\
\hline
\end{tabular}

\section{Interview process}

The focus of the semistructured interviews and focus group discussions was on the safety behaviors employed by parents within the home, factors contributing to child poisoning events, and motivators and barriers to parental uptake of poison safety measures. The protocol for the interviews and focus groups was developed initially from the study goal, which was to understand parental uptake of child poisoning safety practices. It was also guided by the profile of child unintentional poisoning and common features of poisoning incidents accessed through the literature review. This protocol developed dynamically throughout the research process in response to data collection and analysis in a manner consistent with a grounded theory approach. ${ }^{15}$ All the data from the interviews were either written down in note form during the interview (phone interviews only) or recorded on audiotape and transcribed.

\section{Data analysis}

The interview records and transcriptions were entered into $\mathrm{N}$-Vivo qualitative software and analysed using a grounded theory approach. ${ }^{16}$ Names were changed to protect the anonymity of the family; however, the ages of the children were included where known because of the link between parental safety measures and the perceived developmental level of the child. Independent coding was not possible due to resource and time constraints. However, the results of this study replicated the findings of a recent unpublished qualitative study of factors contributing to child unintentional poisoning, supporting the confirmability of the results. ${ }^{1621}$

Ethics approval was provided by the Royal Children's Hospital Research in Humans Ethics Committee.

Table 3 Sociodemographic spread of participants

\begin{tabular}{ll}
\hline Variable & Sample \\
\hline Age & $\begin{array}{l}17-42 \text { years } \\
\text { Privately owned, rental, public, high } \\
\text { rise, grandparent home } \\
\text { Inner city, suburban, outer suburban, } \\
\text { rural town, rural remote, rural property } \\
\text { Geographic location }\end{array}$ \\
$\begin{array}{l}\text { Chinese, Middle Eastern, Somali, East } \\
\text { diverse communities }\end{array}$ & $\begin{array}{l}\text { Timorese, Turkish, Singaporean, } \\
\text { English, South American }\end{array}$ \\
\hline
\end{tabular}




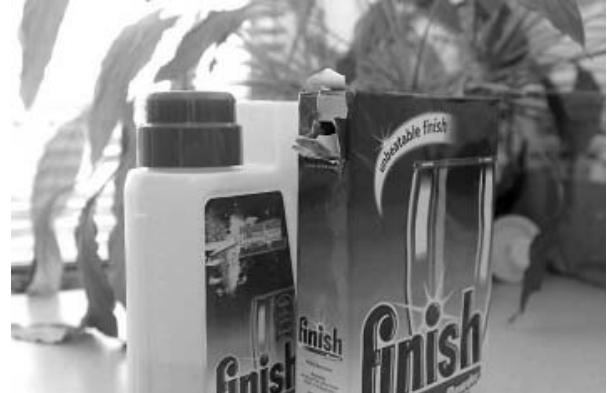

Figure 1 Various toxic household products are provided by manufacturers in both child resistant containers (CRCs) and non-CRCs.

\section{RESULTS AND DISCUSSION}

Parents were aware of the need for poison safety strategies and were implementing strategies to various degrees but not comprehensively in the home. There was a range of knowledge based, environmental, and behavioral factors acting as barriers to comprehensive uptake of poison safety strategies.

\section{Knowledge based barriers}

Limited legislation for child resistant containers (CRCs) exists in Australia, applying to a small number of medications only. Various toxic household products are also provided by manufacturers in both CRCs and non-CRCs, allowing for consumer choice, although CRCs are generally more expensive to purchase (fig 1).

The concept of CRCs was widely supported by parents as an important mechanism for protecting children from toxic products. However, the support for CRCs was often based on the notion that they were childproof rather than child resistant. As a result, some parents were more likely to store products unsafely if they were in CRCs: "If I've got any products down low I make sure they've got a safety cap and if they haven't I put them up high, so I still don't take the risk." (mother of $3 \frac{1}{2}$ year old and 2 year old boys).

This misunderstanding of appropriate storage of CRCs was supported in an unpublished Masters thesis. ${ }^{21}$ However, it contradicts a study by Wiseman et al (1987) who found no difference in storage patterns for products in CRCs and those in non-child resistant packages. ${ }^{22}$ As the introduction of CRCs has been found to have a significant effect on child unintentional poisoning, ${ }^{22-30}$ any indication of a false sense of security in parents should be addressed through education programs and not through reduction in the use of CRCs.

There was also a perception among parents that we live in a protective society; subsequently parental awareness of toxicity was strongly linked to the packaging of the product. Many parents were surprised to discover that products without warning labels or CRCs could be dangerous for children.

\section{Environmental barriers}

The most common safety procedure being used by parents was storage of products, especially medicines, in an overhead cupboard that was out of reach of children. There was little evidence of overhead cupboards being locked despite the fact that the main message for poison safety in Victoria is to store toxic products in a locked cupboard or cabinet. ${ }^{31}$ Storage in overhead cupboards is only possible in homes with adequate overhead storage options.

"But in my bath no cupboard. All I put in the bucket, plastic bucket ... But it's safe ... I close the door but not lock it ... No key. But now he bring that chair." (mother of 2 and 4 year old boys). This mother was reporting on the lack of storage options in her government owned, high rise flat.

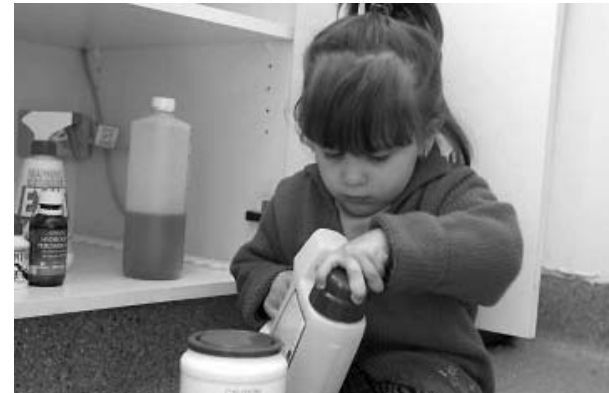

Figure 2 Rapid changes in a child's mobility and interests can result in unexpected access to dangerous areas and products.

Living in public housing, rental properties, or in the home of the grandparents affected parents' abilities to implement safety practices. A regulatory intervention that aimed to ensure that all homes have a lockable poisons cupboard in the kitchen and the laundry/bathroom would help parents to maintain safety standards in the home.

Parents commonly use safety products such as cupboard and drawer locks, gates, and fridge locks to prevent access to storage areas. However, these products were often abandoned when children were able to break them or bypass them. Establishing testing standards that assess the efficacy of safety products would support parents' safety efforts.

\section{Behavioral barriers}

Poison safety practices tended to be only partially implemented in the home. They were more likely to be applied in the kitchen than the laundry or bathroom, and more commonly inside the house than in external laundries, gardens, or sheds. Determination of where and when safety practices should be implemented was often based on the products or areas the child had tried to access previously:

"There are more dangerous things in the laundry but they've never really taken an interest in the laundry stuff." (mother of 3 year old boy and 5 year old daughter).

"Ben's 8 months so he's not into any of that stuff. I don't think to move anything until he's been in it." (mother of 3 year old girl and 8 month old boy).

This "customised" approach to safety measures is tailored to the perceived skill and mobility of the child but often does not account for rapid changes in ability. ${ }^{21}$ It clearly places the child at risk as soon as they explore a new area or product (fig 2), and also places visiting children at risk because safety standards have not been comprehensively addressed.

Some parents were committed to educating their child about toxic products to encourage them to be self-regulating. The difficulty with the self-regulatory approach was that parents often seemed to overestimate the ability of very young children to remember instructions, apply them consistently, and relate them to changed circumstances.

"I think once they're four or three they pretty much know they're not allowed to touch. I think it's two and under, where you're still teaching them, it's like 'don't touch' but they're still trying." (mother of two children).

Convenience is also a factor in the storage of products, particularly relating to contraceptives, medications in use, dishwashing powder, and products used for home based businesses. Some parents felt that if they were too diligent about safe storage of products, to the point that it was inconvenient to access them, then they would be more likely to leave them on the bench on the basis that they would "get to that later".

"Well yeah for something that you want to keep handy and use all the time, you're not going to go and lock it in a bloody 
cupboard are you? You're going to use it and you're gonna go, "yeah I'll put that away later'." (mother of five children).

The issue of convenience is a clear barrier to safe storage and is reflected in the high incidence of children accessing products while they are "in use". Combined home and work environments such as home businesses or a farming environment meant that additional toxic products were potentially accessible to children at a time when parents were focussed on work activities. ${ }^{21}$

\section{Motivators for increased uptake of poison prevention strategies}

The dominant factor likely to shift parents' recognition of personal risk was exposure to a child poisoning event. This usually occurred when their child accessed a dangerous product or area they had previously shown no interest in or had not been able to access. This alerted the parent to the reality of personal risk and motivated them to increase safety measures within the home. Vicarious exposure to a child unintentional poisoning incident was also effective in increasing parents' awareness of the personal reality of risk and the need to increase safety measures in the home. The source of vicarious experiences that was evident in the study was stories shared through family, friends, and parent peers, or profiles of individual incidents reported in the media:

"Yeah, I didn't think until I saw that show [about a baby that died after swallowing baby oil]. As soon as I saw that show I went and got the baby oil because I just used to put it there. I didn't even think." (mother of two children).

Two disconfirming cases to this response were found where parents appeared to be encouraged if their child was unhurt in a poisoning event and perceived it as meaning that poisoning is low risk:

"Metho's [metholated spirits] not poisonous, trust me, my kids have drunk it!" (mother of three children). This may partially explain the pattern of increased risk following a poisoning incident, ${ }^{4}$ suggesting that although parents will process exposure to a poisoning incident to inform future safety practices, the result is not always supportive of increased safety procedures. This indicates that parents' interpretation of poisoning incidents could be a contributory factor in repeat poisonings, which could be addressed through interventions immediately following a poisoning incident. $^{7}$

\section{CONCLUSION}

This study provides an increased understanding of parental use of poison safety practices in the home and in particular the barriers and motivators to increased uptake of safety strategies.

It was found that although poison safety practices were commonly adopted by parents in this study, they were not applied comprehensively in the home due to a tendency to tailor safety measures to the perceived interests and abilities of the resident children and a tendency to alter safe storage behaviors while products are in use. This made children vulnerable to changed circumstances in the home environment and to changes in their own behavior and developmental ability.

The study findings supported the development of legislation requiring the inclusion of a lockable, overhead cupboard in homes and the introduction of testing standards that assess the efficacy of safety products. The results also indicated that parent education programs about warning labels, child resistant containers, safe management of products while "in use", and poison risks following a poisoning incident may contribute to parent awareness of poison safety.

\section{Key points}

- Child unintentional poisoning is a significant public health issue in Victoria where it is the second most common cause of injury hospitalizations for children under five.

- Parental uptake of poison safety strategies is a critical factor in the prevention of child unintentional poisoning.

- Parental selection of safety practices was often guided by the interests and behaviors of the child, resulting in incomplete application of safety measures.

- Personal or vicarious exposure of a parent to a child poisoning incident was a significant motivator for increased uptake of safety practices.

Vicarious or personal exposure to a child poisoning incident was identified as a dominant motivator for a review of safety behaviors among the parents in this study. This suggests that interventions based on the circulation of stories of actual child poisoning incidents may be effective in increasing parents' awareness of the reality of risk. Examples of severe cases may be needed to target parents who have a false sense of security following a poisoning incident with a positive outcome.

Further quantitative research would help in evaluating the effectiveness of interventions targeting parental motivators/ barriers and subsequent uptake of safety practices, and the impact of increased safety practices on incidence of child unintentional poisoning. In depth research with culturally and linguistically diverse communities would also provide greater understanding of sociocultural differences in risk/ protective factors operating in relation to child unintentional poisoning.

\section{ACKNOWLEDGEMENTS}

This paper is based on a project commissioned by the Department of Human Services Victoria. It was undertaken by the Centre for Community Child Health in partnership with the Monash University Accident Research Centre and with the support of the Child and Youth Injury Prevention Alliance. The authors gratefully acknowledge the generosity of parents who shared their time and life experiences, and the support of the VPIC staff, and RCHED nurses Milli McLeish and Naomi Oborne.

\section{Authors' affiliations}

L Gibbs, E Waters, School of Health and Social Development, Deakin University, Victoria, Australia

J Sherrard, J Ozanne-Smith, Monash University Accident Research Centre, Victoria, Australia

J Robinson, Victorian Poisons Information Centre, Victoria, Australia S Young, A Hutchinson, Emergency Medicine, Royal Children's Hospital, Victoria, Australia

\section{REFERENCES}

1 Stathakis V. Hospitalised injuries Victoria, July 1992-June 1998, Monash University Accident Research Centre, 1999. Report no: 160.

2 Commonwealth Department of Health and Aged Care. National injury prevention plan: Priorities for 2000-2002, Commonwealth of Australia, 1999.

3 Ozanne-Smith J, Day L, Parsons B, et al. Childhood poisoning: access and prevention. J Paediatr Child Health 2001;37:262-5.

4 Petridou E, Kouri N, Polychronopoulou A, et al. Risk factors for childhood poisoning: a case-control study in Greece. Inj Prev 1996;2:208-11.

5 Mclntyre MS, Angle CR, Grush ML. How effective is safety packaging? Clin Toxicol 1976;9:419-25.

6 Woolf A, Lewander W, Filippone G, et al. Prevention of childhood poisoning:efficacy of an educational program carried out in an emergency clinic. Pediatrics 1987;80:359-63. 
7 Woolf A, Saperstein A, Forjuoh S. Poisoning prevention knowledge and pactices of parents after a childhood poisoning incident. Pediatrics 1992;90:867-70

8 Quinlan KP, Sacks JJ, Kresnow J. Exposure to and compliance with pediatric injury prevention counseling-United States, 1994. Pediatrics 1998;102:e55.

9 Clamp M, Hendrick D. A randomised controlled trial of general practitioner safety advice for families with children under 5 years. BMJ 1998;316:1576-9.

10 DiGuiseppi C, Roberts I. Individual-level injury prevention strategies in the clinical setting. Future Child 2000; 10:53-82.

11 Kreuter M, Oswald D, Bull F, et al. Are tailored health education materials always more effective than non-tailored materials? Health Educ Res 2000; 15:305-15.

12 Nansel T, Weaver N, Donlin M, et al. Baby Be Safe: the effect of tailored communications for pediatric injury prevention provided in primary care setting. Patient Educ Couns 2002;46:175-90.

13 Rey S, Courtois X, Zmirou D, et al. Evaluation of an educational action on accident prevention in children. Pediatrie 1993;48:727-33.

14 Liller K, Craig J, Crane N, et al. Evaluation of a poison prevention lesson for kindergarten and third grade students. Inj Prev 1998;4:218-21.

15 Glaser B, Strauss AL. The discovery of grounded theory: strategies for qualitative research. New York: Aldine De Gruyter, 1967.

16 Strauss AL, Corbin J. Basics of qualitative research: grounded theory procedures and techniques. London: Sage Publications, 1990.

17 Ozanne-Smith J, Routley V, Scott I, et al. Pharmaceutical poisonings to 0-19 year olds. Victoria: National Public Health Partnership Public Health Planning and Practice Framework Trial, Monash University Accident Research Centre, 2002 Nov. Report no: 193.
18 Robinson J. Annual report 2002. Melbourne: Victorian Poisons Information Centre, Royal Children's Hospital, 2002.

19 Russell G. Sharing the pleasures and pains of family life. Fam Matters 1994; No 37:13-19.

20 Lincoln Y, Guba E. Naturalistic inquiry. Beverly Hills, California: Sage, 1985.

21 Jolly K-A. Investigation of the factors influencing unintentional medication poisoning in children under 5 years. La Trobe University, 2003 [Masters]

22 Wiseman HM, Guest K, Murray VSG, et al. Accidental poisoning in childhood: A multi-centre survey. 2 . The role of packaging in accidents involving medications. Hum Toxicol 1987:6:303-14.

23 Breault HJ. Five years with 5 million child-resistant containers. Clin Toxicol 1974;7:91-5

24 Rodgers GB. The safety effects of child-resistant packaging for oral prescription drugs. JAMA 1996;275:1661-5.

25 Sibert J. Child-resistant packaging and accidental child poisoning. Lancet 1977;8032:289-90

26 Rodgers GB. The effectiveness of child-resistant packaging for aspirin. Arch Pediatr Adolesc Med 2002;156:929-33.

27 Consumer Product Safety Commission. Poison prevention packaging: A text for pharmacists and physicians, In: CPSC, ed. Washington DC, 1999.

28 Clarke MA, Walton WW. Effect of safety packaging on aspirin ingestion by children. Pediatrics 1979;63:687-93.

29 Schieber RA, Gilchrist J, Sleet D. Legislative and regulatory strategies to reduce childhood unintentional injuries. Future Child 2000;10:111-36.

30 Walton WW. An evaluation of the Poison Prevention Packaging Act. Pediatrics 1982;69:363-70.

31 Victorian Poisons Information Centre. http://www.rch.unimelb.edu.au/ poisons. 2003. 